\title{
El factor demogràfic en la sostenibilitat del sistema de pensions a Espanya
}

\section{Albert Esteve, Daniel Devolder i Amand Blanes, Centre d'Estudis Demogràfics}

La caiguda dels naixements, l'augment de l'esperança de vida i la jubilació futura dels baby-boomers desafia la sostenibilitat del sistema de pensions a Espanya perquè disminueix la relació entre cotitzants i jubilats. En aquest número del Perspectives Demogràfiques examinem la incidència d'aquestes causes sobre la sostenibilitat demogràfica del sistema il'efecte que diversos escenaris de mortalitat, fecunditat i migració exterior podrien tenir en el futur. Les condicions demogràfiques del passat, molt favorables pel sistema, no es repetiran en el futur, però la demografia del futur no hauria de ser obstacle per mantenir un sistema de pensions, basat en la idea de repartiment, sostenible, solidari i suficient.

\section{AVUI PER TU, DEMÀ PER MI}

El sistema de pensions a Espanya està basat en un pacte solidari entre generacions. Les persones ocupades generen cotitzacions que, gestionades per la Seguretat Social, s'utilitzen per pagar les pensions de les persones que en el passat van adquirir el dret a percebre una pensió vitalícia de jubilació. La sostenibilitat del sistema depèn de la diferència entre el volum de cotitzacions i el de les pensions. Aquests, al mateix temps, depenen principalment de factors econòmics i demogràfics. Entre els econòmics destaquen les taxes d'ocupació i el nivell de salaris, estretament relacionats amb la productivitat de l'economia. I, entre els demogràfics, els factors més importants són la grandària i la duració de les cohorts de naixement. La grandària es refereix al número de persones que constitueix una cohort, que és resultat de la fecunditat/naixements del passat, la mortalitat i les sortides i entrades per migració. La duració correspon a la vida mitjana que transcorre des de que neix una cohort fins que moren tots els seus membres i, a efectes del càlcul de les pensions, des de que es jubilen fins que moren. Grandària i duració condicionen la relació entre la població activa/ocupada i la jubilada. Com més població ocupada hi ha respecte la jubilada, més sostenible és el sistema. El persistent augment de l'esperança de vida i la caiguda i estancament de la fecunditat per sota de 1,5 fills per dona disminueix - i ho seguirà fent - la relació entre la població en edat de treballar i la jubilada, momentàniament alleugerida per la incorporació al mercat de treball de les generacions plenes nascudes entre 1960 i 1975, els baby-boomers. No obstant, la jubilació propera dels baby-boomers juntament amb l'entrada de generacions buides al mercat laboral ha disparat les alarmes sobre la sostenibilitat del sistema de pensions a Espanya i en la majoria de països occidentals.

\section{LA SOSTENIBILITAT DEMOGRÀFICA DEL SISTEMA DE PENSIONS: PASSAT I PRE- SENT}

L'Indicador de Sostenibilitat Demogràfica (ISD) del sistema de pensions mesura la relació entre el volum de cotitzacions i el volum de pensions de jubilació en funció de la demografia (distribució per edat i sexe) de cada moment (Fig. 1). Aquest indicador assumeix un perfil econòmic i constant en el temps. Assumim aquí l'estructura de renda laboral, les taxes d'ocupació i d'atur, les cotitzacions i les pensions de 2012 constants en el temps, retrospectivament i cap al futur. En aquell any, la cotització mitjana representava el $23 \%$

FIGURA 1. La sostenibilidat demogràfica del sistema de pensions a Espanya, 1970-2070

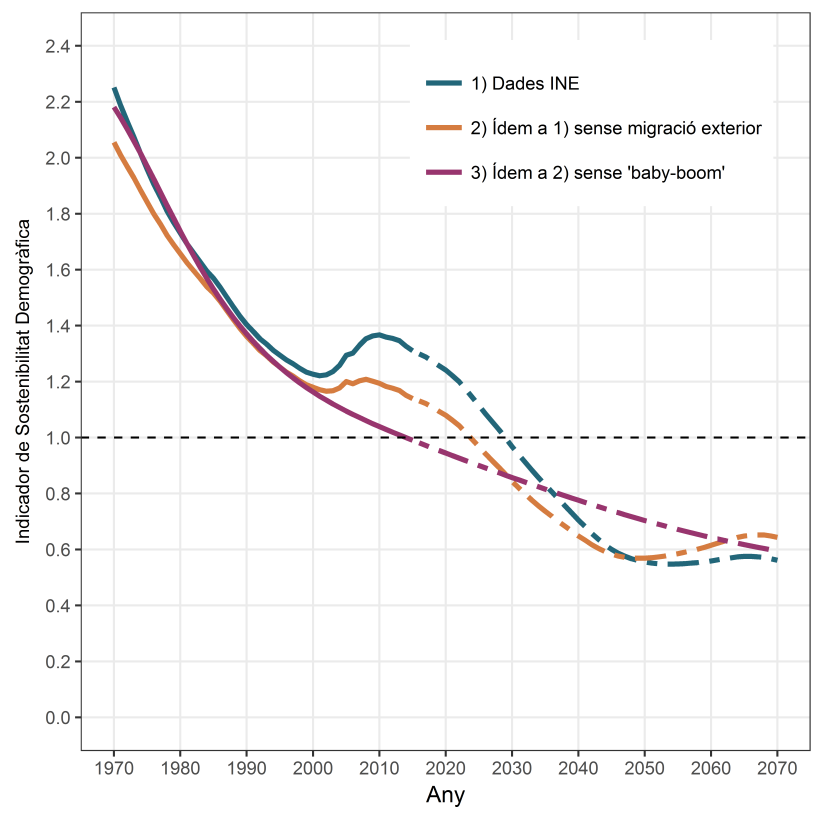

Font: Elaboració amb dades INE i càlculs propis. 
del salari i l'import de la jubilació equivalia de mitjana al 60\% de l'últim salari. El sistema és sostenible (ISD igual o major a 1) quan les cotitzacions generades per la població cotitzant són iguals o superiors a les pensions demandades per la població receptora de pensions. Òbviament, el nivell absolut de l'indicador varia en funció del perfil econòmic de referència, però per poder aillar l'efecte demogràfic és precís utilitzar un únic perfil de referència. Per tant, ens centrarem més en l'evolució de l'indicador en el temps que en els seus valors absoluts.

La Figura 1 mostra l'evolució de l'ISD entre 1970 i 2070 en funció de tres escenaris. El primer escenari està basat en l'evolució demogràfica observada fins a 2015 i la projectada es basa en l'escenari mitjà de les projeccions publicades per l'INE a l'any 2016. El segon escenari pregunta què li hauria passat a l'indicador de sostenibilitat sense la immigració internacional arribada a Espanya durant les últimes dos dècades. El tercer afegeix una suposició addicional: substitueix l'evolució dels naixements observats per una evolució tendencial i moderada dels naixements en el passat. Els tres escenaris mostren que Espanya s'ha beneficiat d'unes condicions demogràfiques molt favorables per al manteniment del sistema de pensions. Assumint el perfil econòmic de 2012, les cotitzacions a l'any 1970 haurien sumat el doble d'ingressos del que el sistema exigia en pensions de jubilació. Nogensmenys, entre 1970 i 2000, l'indicador de sostenibilitat decreix fins a 1,2 (les cotitzacions són un $20 \%$ superiors a les pensions). La caiguda de l'indicador s'atura i el nivell es manté per sobre de l'1,2 fins l'any 2022 gràcies a la incorporació de les generacions del baby-boom al mercat de treball i a l'arribada de la immigració internacional. Sense baby-boom i sense immigració internacional les tensions demogràfiques en el sistema de pensions serien avui més grans, en concret, l'ISD seria un 30\% més baix. És important observar també que des d'una perspectiva estrictament demogràfica, la sostenibilitat del sistema seria avui major que la de l'any 2000.

\section{TENDĖNCIES (I SOLUCIONS DEMOGRÀFI- QUES?) A CURT I MITJÀ TERMINI}

Els panells de la Figura 2 representen l'indicador de sostenibilitat demogràfica projectada fins l'any 2070 segons diferents escenaris de futur sobre l'evolució de la mortalitat / esperança de vida (panell 1), la fecunditat (panell 2) i les migracions internacionals (panell 3). Si la mortalitat es mantingués constant en el futur al nivell de 2015, la sostenibilitat demogràtica del sistema de pensions cauria fins a o,72 el 2045 (contribucions inferiors en un $28 \%$ a les pensions). $\mathrm{Si}$ augmentés l'esperança de vida en el futur al ritme de les darreres dècades, l'indicador de sostenibilitat cauria fins a o,6 l'any 2045. El 83\% del descens de la sostenibilitat demogràica fins el 2045 és directament atribuïble a l'efecte de la variació de la grandària de les cohorts que es jubilen (els baby-boomers) i el 17\% a l'augment de l'esperança de vida (la seva durada). Aquest càlcul resulta de comparar la disminució de l'ISD entre 2015 i 2040 sense i amb augment de l'esperança de vida.

Per mesurar l'impacte de la recuperació de la fecunditat sobre la sostenibilitat demogràica del sistema de pensions treballem amb dos escenaris de creixement de la fecunditat (veure Figura 2 panell 2). En el primer, la fecunditat creix tendencialment de 1,33 fills per dona a 2,1 entre 2016 i 2100. En el segon, la fecunditat arriba als 2,1 fills per dona l'any 2040 i posteriorment es manté constant en aquest nivell. La recuperació de la fecunditat té efectes modestos a

FIGURA 2. La sostenibilitat demogràfica futura del sistema de pensions segons diferents escenaris sobre la mortalitat, la fecunditat i la migració
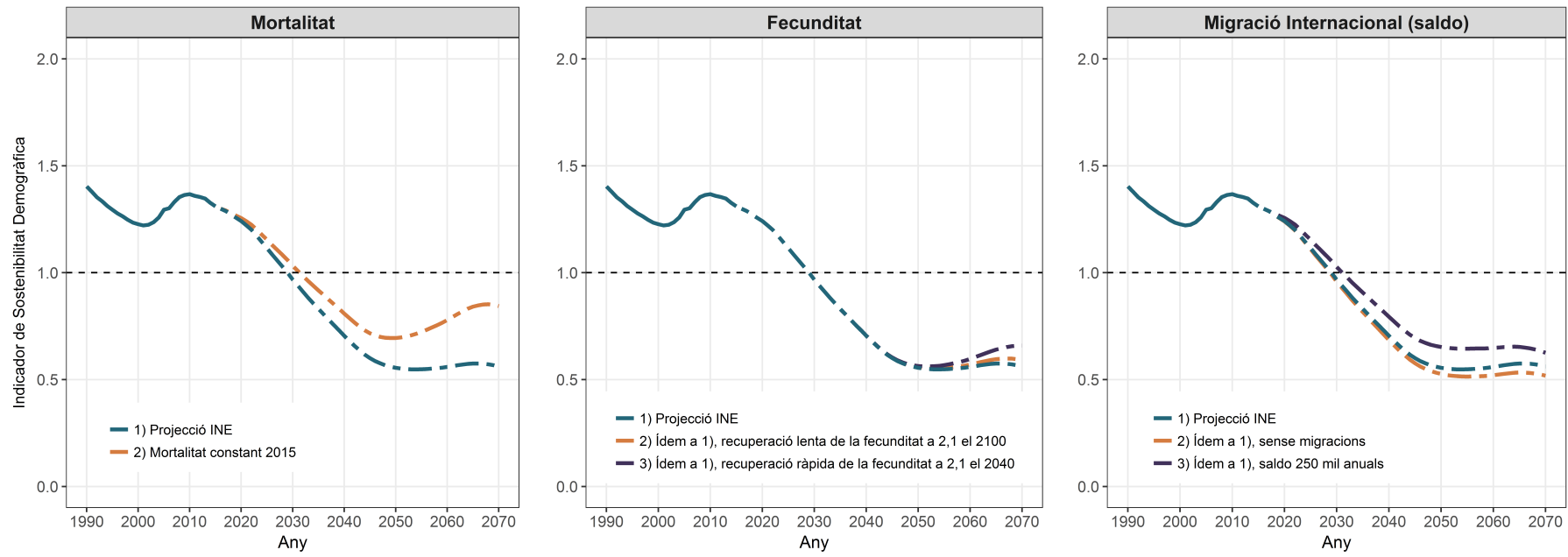

Font: Elaboració amb dades INE i càlculs propis. 
llarg termini sobre la sostenibilitat demogràfica del sistema, però els efectes són imperceptibles abans de 2050. La recuperació ràpida de la fecunditat (segon escenari) milloraria la sostenibilitat del sistema l'any 2070, tot i que no seria suficient per revertir-ne la caiguda.

La immigració té, a curt termini, efectes positius sobre la sostenibilitat demogràfica del sistema (veure panell 3 Figura 2). Tot i així, a mitjà i a llarg termini els immigrants també es jubilen. Un saldo migratori moderadament positiu i constant en el temps de 12 mil persones/any el 2016 a 80 mil a partir de 2065 segons l'última previsió de l'INE, milloraria lleugerament els índexs de sostenibilitat envers l'escenari sense creixement migratori. Si el saldo augmentés fins a xifres de 250 mil persones anuals, l'indicador creixeria en 10 punts fins l'any 2050 (de 0,55 fins a 0,65). A llarg termini, al 2070, cap escenari seria suficient per revertir la caiguda de l'indicador de sostenibilitat.

\section{L'EDAT A LA JUBILACIÓ}

Des d'un punt de vista teòric, retardar l'edat a la jubilació és una solució senzilla per garantir la sostenibilitat demogràfica del sistema de pensions. Amb això, el període de cotització s'allarga i el de jubilació s'escurça. La Figura 3 mostra l'edat a la jubilació que mantindria el sistema en equilibri segons dos escenaris. El primer escenari reflecteix les condicions demogràfiques observades entre 1970 i 2015 i les projectades per l'INE fins al 2070. L'any 1970, gràcies a les condicions demogràfiques favorables del país, l'edat a la jubilació s'hagués pogut fixar als 56,8 anys, 4,5 anys per sota de l'estimada l'any 2016. La incorporació plena dels baby-boomers al mercat de treball, sumada a l'arribada de la immigració internacional, hagués permès disminuir l'edat a la jubilació de 62,3 el 1999 a 60,7 el 2009, any a partir del qual creixeria fins als 73,8 l'any 2058 quan les generacions del baby-boom estaran jubilades completament. Les oscil-lacions observades a l'edat a la jubilació d'equilibri reflecteixen l'entrada i la sortida del mercat de treball de cohorts de diferents grandàries.

El segon escenari reflecteix l'evolució de l'edat a la jubilació d'equilibri en un model de població que repeteix les condicions de mortalitat del primer escenari, però assumeix una tendència d'evolució dels naixements entre el -0.2\% i el o,2\% anual. Aquest model de població no està subjecte a variacions brusques en el número de naixements degut, per exemple, als efectes conjunturals del baby-boom. Tampoc contempla sortides i entrades per migració. La diferència a l'edat de jubilació d'equilibri entre el llindar de màxim creixement $(0,2)$ i el mínim $(-0,2)$ és de 2 anys. En aquest model, l'edat a la jubilació d'equilibri augmenta segons creix
FIGURA 3. Edat a la jubilació necessària per mantenir el sistema en equilibri segons diferents escenaris de població

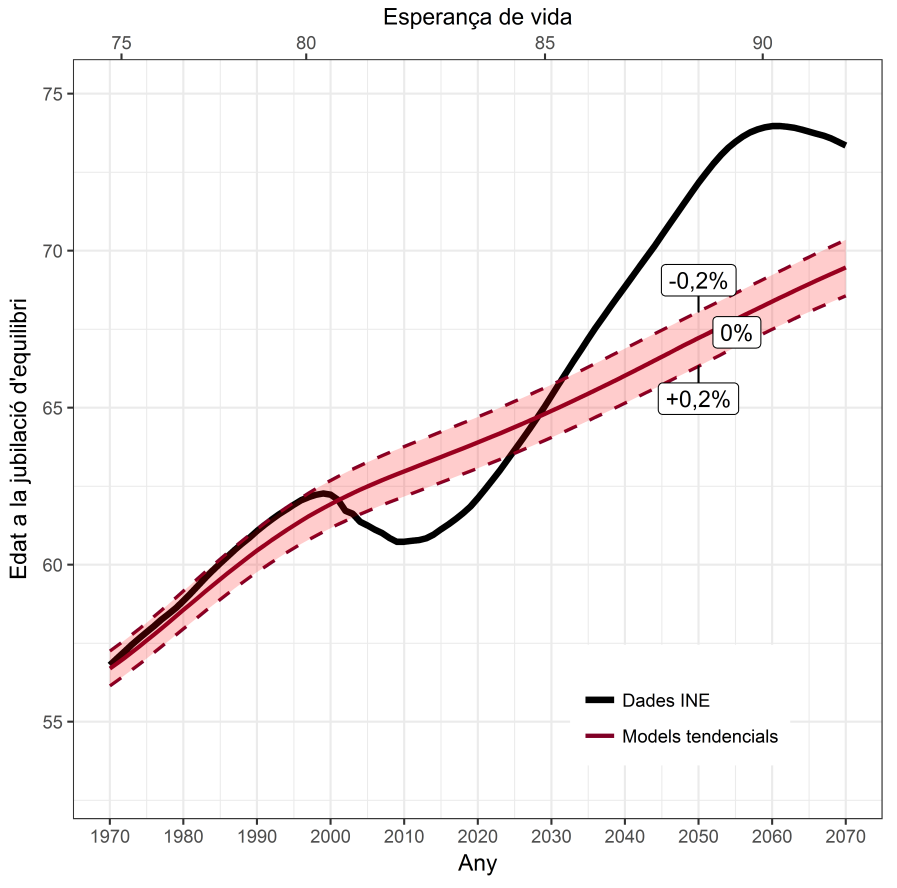

Font: Elaboració amb dades INE i càlculs propis.

Nota: La corba negra està basada en la población observada fins 2015 i la projectada per l'INE. La corba vermella està basada en un model que té en compte principalment els canvis en la mortalitat sense migracions ni fluctuacions en la natalitat.

l'esperança de vida. L’any 2030, l'edat a la jubilació d'equilibri se situaria als 65 anys en els dos escenaris. A partir d'aquest any, la jubilació dels baby-boomers obligaria a retardar l'edat a la jubilació a un ritme més gran del que seria necessari si només tinguéssim en compte l'augment de l'esperança de vida. A l'any 2050, la diferència entre un escenari amb o sense baby-boomers és de gairebé 6 anys.

\section{LA VIABILITAT DEMOGRÀFICA DEL SISTE- MA: UNA REFLEXIÓ DE CONJUNT}

En els últims quaranta anys, la societat espanyola ha consolidat un sistema de pensions basat en la idea de repartiment sobre unes condicions demogràfiques irrepetiblement favorables. Unes condicions basades en el creixement continuat de la població activa, en una edat a la jubilació relativament alta pels nivells d'esperança de vida de l'època i en la jubilació d'unes cohorts escasses i castigades per una mortalitat més elevada que l'actual. Per contra, el futur depara unes condicions radicalment diferents davant de la jubilació dels baby-boomers, el creixement de l'esperança de vida i l'entrada al mercat laboral de generacions buides. En conseqüència, la sostenibilitat futura del sistema de pensions no podrà recolzarse en la demografia. Ni una poc probable recuperació ràpida de la 
fecunditat ni un saldo migratori positiu de fins a 250 mil entrades anuals podrien revertir els efectes en el sistema de la jubilació dels baby-boomers, i el creixement de l'esperança de vida. No obstant, això no significa que la demografia del futur sigui un obstacle per la viabilitat del sistema de pensions. Ajustar els períodes de cotització i jubilació en funció de l'esperança de vida és una mesura raonable per quadrar les xifres. Ara bé, aquest ajustament hauria de basar-se exclusivament en els guanys d'esperança de vida i no en les necessitats del sistema per quadrar els comptes davant la jubilació de generacions de major o menor grandària. En efecte, penalitzar unes generacions i no unes altres en funció de la seva grandària constituiria clarament una desigualtat intergeneracional.

En aquest exercici hem deixat intencionadament al marge l'impacte de les variacions econòmiques en el sistema per aillar l'efecte del canvi demogràfic de forma nítida. Lògicament, si modifiquéssim els paràmetres econòmics, els nivells de sostenibilitat demogràfica del sistema de pensions variarien. Per exemple, segons el nostre model, l'augment d'un punt percentual en el nivell de cotització, és a dir, passar del $23 \%$ al $24 \%$ de salari, permetria reduir entre 5 i 7 mesos l'edat d'equilibri a la jubilació i retardaria entre 3 i 5 anys el moment en el qual el sistema entraria en dèficit. L'economia espanyola té ampli recorregut per millorar els seus nivells de productivitat i activitat. L'augment de l'activitat i ocupació entre els joves i la població més gran de 60 anys o l'equiparació de les taxes d'activitat femenina amb les masculines tindrien efectes positius sobre la sostenibilitat del sistema a curt i mitjà termini. Si l'economia espanyola sap capitalitzar i millorar la productivitat dels seus actius, la demografia no posarà obstacle a la viabilitat del sistema.

La demografia de les altes esperances de vida, dels naixements minvants, del creixement de la població a expenses dels moviments migratoris, i de les piràmides transformades en obeliscs ha vingut per quedar-se. Però això no implica que els sistemes de pensions basats en la idea de repartiment no siguin sostenibles en aquestes condicions. Per això, s'hauran d'adequar els períodes de treball i jubilació als increments nets d'esperança de vida d'una forma justa i equitativa amb el tipus de treball i l'esforç que han realitzat les generacions en el passat, amb independència de la seva grandària. La sostenibilitat futura exigeix millores en la productivitat de l'economia i canvis en la provisió econòmica del sistema. En cas contrari, la confiança de la ciutadania en el sistema de pensions disminuiria i això suposaria un desafiament pel sistema de major abast que el demogràfic.

\section{Referències bibliogràfiques}

BLANES, Amand; CABRÉ, Anna (2015) "Inercias e incertidumbres en el futuro demográfico de España”. Revista del Ministerio de Empleo y Seguridad Social, 119 ("Seguridad Social"): 105-129.

FERNÁNDEZ CORDÓN, Juan Antonio (2015) "Relaciones intergeneracionales, demografía y economía en relación con las pensiones", Cuadernos de relaciones laborales, 33 (2): 235-258.

INSTITUTO NACIONAL DE ESTADÍSTICA (2016) "Proyecciones de la población de España, 2016-2066. Metodología”, Madrid, www.ine.es.

LEE, Ronald D; MASON, Andrew (2011) "Population Aging and the Generational Economy: A Global Perspective", Cheltenham, Edward Elgar.

\section{Cita}

Albert Esteve, Daniel Devolder Amand Blanes (2018) "El factor demográfico en la sostenibilidad de sistema de pensiones en España", Perspectives Demogràfiques, 9: 1-4.

Editors

Andreu Domingo i Albert Esteve

Correspondència dirigida $\mathrm{a}:$

Albert Esteve

aesteve@ced.uab.cat

Crèdits

Gràfics: Anna Turu

Maquetació: Xavier Ruiz Vilchez

Agraïments

Elisenda Rentería i Rocío Treviño

\section{Enllaç url}

http://ced.uab.es/difusio/butlleti-pers-

pectives-demografiques

Contacte

Centre d'Estudis Demogràtics.

Carrer de Ca n'Altayó, Edifici E2

Universitat Autònoma de Barcelona

o8193 Bellaterra / Barcelona

Espanya

Telèfon: + 34935813060

Correu:demog@ced.uab.es

Web: http://ced.uab.es/ 